\title{
Caracterização ambiental e predição dos teores de matéria orgânica do solo na Sub-Bacia do Salto, Extrema, MG $^{1}$
}

\section{Environmental characterization and soil organic matter prediction for Salto Watershed, Extrema, MG}

\author{
Anna Hoffmann Oliveira ${ }^{2}$; Mayesse Aparecida da Silva ${ }^{3 *}$; \\ Marx Leandro Naves Silva ${ }^{4}$; Junior Cesar Avanzi ${ }^{5}$; Nilton Curi ${ }^{4}$; \\ Gabriela Camargos Lima ${ }^{3}$; Paulo Henrique Pereira ${ }^{6}$
}

\section{Resumo}

O manejo racional em uma bacia hidrográfica requer o conhecimento de diversos parâmetros, entre eles a morfometria, a cobertura vegetal e o teor de matéria orgânica do solo (MOS). Os objetivos do trabalho foram avaliar as características morfométricas, a presença de vegetação utilizando o índice de vegetação por diferença normalizada (NDVI), e a distribuição espacial dos teores de matéria orgânica do solo (MOS) obtida a partir da combinação dos atributos da paisagem na Sub-bacia Hidrográfica do Salto, no município de Extrema, MG. Foram utilizados mapas topográficos digitalizados, imagens de satélite e o modelo de regressão linear múltipla relacionando os atributos da paisagem com o teor de MOS para obter a distribuição espacial da MOS. A Sub-bacia do Salto possui tendência mediana a enchentes, a drenagem é eficiente e bastante ramificada. Grande parte da sub-bacia encontra-se ocupada por pastagens degradadas e a vegetação com grande quantidade de biomassa ocorre principalmente nas áreas de cabeceira. $\mathrm{O}$ conjunto de atributos que melhor estimou o teor de MOS foi declividade, perfil de curvatura, NDVI e índice topográfico de umidade (TWI). A MOS apresentou teor médio $(2,01$ a 4,00 dag $\mathrm{kg}^{-1}$ ) na maior parte da área estudada, situados principalmente em áreas de maior altitude (cerca de $1.600 \mathrm{~m}$ ) nas cabeceiras da Sub-bacia.

Palavras-chave: Morfometria, índice de vegetação por diferença normalizada (NDVI), matéria orgânica

\begin{abstract}
Rational management in a watershed requires knowledge of several important parameters regarding the hydrology, including morphometric, vegetation cover and soil organic matter (MOS) amounts. The objectives of this study were to evaluate the morphometric characteristics, identify the existence of vegetation using the normalized difference vegetation index (NDVI) and analyze the spatial variability of the organic matter amount, obtained through combination of landscape properties of the Salto Subbasin, Extrema, MG, Brazil. Digitalized topographic maps, satellites images and the Inverse Distance Weighted interpolation methods were used to acquire the MOS spatial variability. The Salto Sub-basin has a median tendency for flooding; drainage is efficient and highly branched. Most part of the Sub-basin is occupied by degraded pastures with vegetation with high biomass occurs mainly in headwater areas.
\end{abstract}

1 Trabalho apresentado na forma de resumo no 19th World Congress of Soil Science, 2010.

2 Eng ${ }^{\mathrm{a}}$ Florestal, $\mathrm{Dr}^{\mathrm{a}}$ do Dept ${ }^{\mathrm{o}}$ de Ciência do Solo, Universidade Federal de Lavras, UFLA. Lavras, MG. E-mail: anna.ufla@gmail.com

3 Engenheiras Florestais, Doutorandas, Dept ${ }^{\circ}$ de Ciência do Solo, UFLA, Lavras, MG. Bolsista da CAPES. E-mail: mayesse@, gmail.com; gabslima@yahoo.com.br

4 Engenheiros Agrônomos, Profs. Drs. do Dept ${ }^{\circ}$ de Ciência do Solo, UFLA, Lavras, MG. Bolsistas do CNPq. E-mail: marx@dcs. ufla.br; niltcuri@dcs.ufla.br

5 Eng ${ }^{\circ}$ Agrícola, Dr. Pesquisador da Embrapa Pesca e Aquicultura, Palmas, TO. E-mail: junior.avanzi@embrapa.br

6 Diretor do Dept ${ }^{\circ}$ de Meio Ambiente, Prefeitura Municipal de Extrema. Extrema, MG. E-mail: meioambiente@extrema.mg.gov.br Autor para correspondência 
The properties set that better estimated the MOS was slope, profile curvature, NDVI and topographic wetness index (TWI). In most of the study area, MOS showed medium amount (2.01 to $4.00 \mathrm{dag} \mathrm{kg}^{-1}$ ), with higher levels in areas of high altitudes (about 1,600 m) at the headwaters of the Sub-basin.

Key words: Morphometric, normalized difference vegetation index (NDVI), organic matter

\section{Introdução}

Uma bacia hidrográfica pode ser compreendida como a área da superfície terrestre drenada por um rio principal, limitado por um divisor de águas e de contribuição para determinados cursos d'água. Nela ocorre a captação da precipitação da água que é descarregada através de uma única saída denominada ponto de exutório (TUCCI, 1997). A bacia hidrográfica contribui, também, no ciclo hidrológico por meio da infiltração e escoamento superficial, abastecendo aquíferos, rios e reservatórios. Juntamente com a água, diversos materiais e sedimentos são transportados para o corpo do rio principal, seja por efeito natural ou antrópico, propiciando a modelagem da paisagem. Devido às suas características intrínsecas, a bacia é uma unidade importante no estudo de atividades ligadas ao uso e conservação dos recursos naturais (BRASIL, 1997).

$\mathrm{Na}$ caracterização ambiental, o diagnóstico dos atributos ambientais que atuam na bacia hidrográfica auxilia na compreensão dos processos de infiltração e erosão hídrica que ocorrem, permitindo o adequado planejamento do uso do solo e a sua conservação. Entre os atributos ambientais, destacase o Índice de Vegetação por Diferença Normalizada (NDVI), que constitui uma importante estratégia para o monitoramento das alterações naturais ou produzidas pelo homem, nos ecossistemas. Este índice apresenta grande sensibilidade à resposta espectral da vegetação e consequentemente pode ser utilizado em estudos de modelagem climática e hidrológica; balanço de carbono, detecção de mudanças climáticas, estimativas de parâmetros da vegetação (cobertura vegetal, índice de área foliar); atividades agrícolas (monitoramento do ciclo de crescimento de culturas, modelagem do crescimento e produtividade de plantações); monitoramento de secas; detecção de desmatamentos, avaliação de áreas queimadas, entre outras aplicações (MOREIRA; SHIMABUKURO, 2004).

Além da vegetação, a topografia desempenha importante papel na redistribuição da água na paisagem, podendo afetar os atributos do solo, distribuição e abundância de água no solo, a susceptibilidade das paisagens à erosão hídrica e a distribuição e abundância de flora e fauna (WILSON; GALLANT, 2000). Entre os atributos ambientais relativos à topografia, o índice topográfico de umidade (TWI), a declividade, o plano e perfil de curvatura (pedoforma) tem grande importância no planejamento do uso do solo em bacias hidrográficas e caracterização do conteúdo de água nas paisagens.

O TWI é um modelo hidrológico que considera a área de contribuição e a declividade do terreno emuma bacia hidrográfica na caracterização, distribuição espacial e identificação das zonas de saturação que irão determinar o início do escoamento superficial (BEVEN; KIRKBY, 1979). Ainda em função da declividade e o tipo da pedoforma, a erosão hídrica em determinada região poderá apresentar áreas mais suscetíveis e outras menos. A pedoforma côncava favorece a convergência das águas levando a uma erosão mais localizada com tendência a formação de voçorocas e sulcos e deposição de material nas partes mais baixas, enquanto a pedoforma convexa favorece a divergência de águas com erosão mais uniforme e laminar, sendo que nesta última temse somente erosão com a retirada de material do sistema (RESENDE, 1985). De acordo com Pei et al. (2010), esses atributos apresentam boa correlação com o teor de matéria orgânica do solo (MOS) sendo utilizados para melhorar a qualidade e reduzir os custos de amostragem.

A matéria orgânica tem um grande efeito na estruturação dos solos, atuando diretamente na manutenção das partículas de areia, silte e argila juntas na forma de agregados, e atuando 
indiretamente através da atividade de muitos organismos, produzindo eles mesmos alterações no solo e dificultando a erosão(RESENDE, 1985). Além disso, os resíduos vegetais em contato direto com a superfície do solo são muito eficazes na redução da carga de sedimentos no escoamento superficial, pois, sob tal forma, eles formam uma intrincada rede filtrando os sedimentos em suspensão na enxurrada (BERTONI; LOMBRADI NETO, 2005). Assim, a perda de matéria orgânica representa um dos principais processos de degradação do solo, pois, além de aumentar a erosão, afeta a qualidade do solo e causa alterações nos regimes de suprimento de água e nutrientes, na lixiviação e acidificação do solo, e redução da atividade biológica (LAL, 2001).

Os objetivos do trabalho foram avaliar as características morfométricas, a presença de vegetação utilizando o índice de vegetação por diferença normalizada (NDVI), e a distribuição espacial dos teores de matéria orgânica do solo (MOS) obtida a partir da combinação dos atributos da paisagem na Sub-bacia Hidrográfica do Salto, no município de Extrema, MG.

\section{Material e Métodos}

\section{Caracterização do local}

A Sub-bacia Hidrográfica do Salto está inserida na Bacia Hidrográfica do Rio Jaguari, no município de Extrema, MG, entre as coordenadas UTM 373000 e 379000 E e 7469000 e $7474500 S$, zona 23 (Datum SAD 69). Segundo a classificação de Köppen, o clima da região é do tipo $\mathrm{Cwb}$, clima subtropical de altitude com inverno seco e verão ameno, precipitação média anual de $1.181 \mathrm{~mm}$ (ANA, 2008), altitude de $1.130 \mathrm{~m}$ e vegetação nativa Mata Atlântica (Figura 1). O mapa de solos foi preparado a partir das informações obtidas durante a caracterização dos perfis modais segundo Santos et al. (2005) e a classificação taxonômica, segundo Embrapa (2006), sendo identificadas as seguintes classes de solos: Neossolos Litólicos e Flúvicos, Cambissolos Háplicos e Húmicos, Argissolo Vermelho-Amarelo e Latossolos. A caracterização ambiental da Sub-bacia do Salto foi realizada a partir da análise das características morfométricas, presença de vegetação e distribuição espacial dos teores de matéria orgânica do solo (MOS), conforme fluxograma apresentado na Figura 2.

Figura 1. Localização do município de Extrema, MG, com destaque para a Sub-bacia do Salto, os pontos amostrados para análise da matéria orgânica do solo (MOS), e a imagem da Sub-bacia e entorno obtida pelo satélite Landsat5 TM, composição do visível RGB 321 para o dia 03 de setembro de 2008.
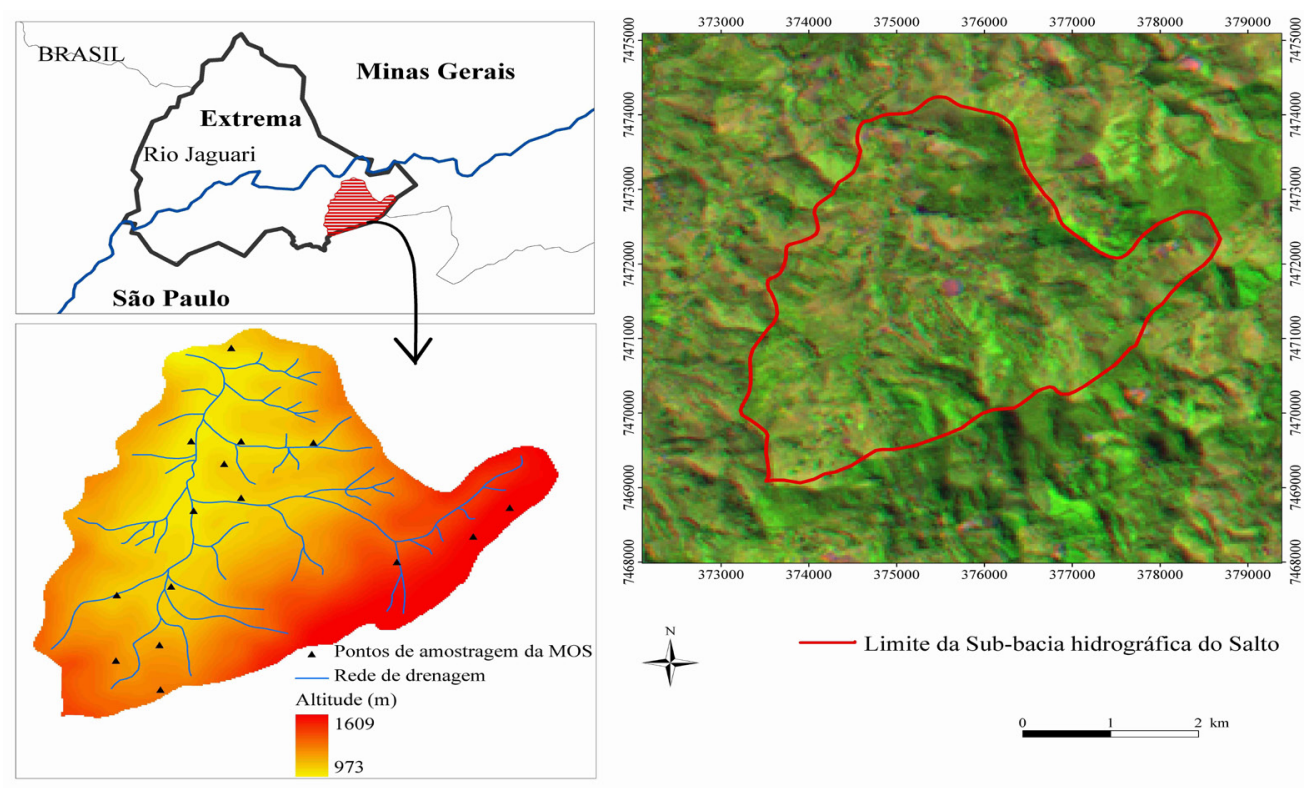

Fonte: Elaboração dos autores. 
Figura 2. Fluxograma das análises realizadas para caracterização ambiental da Sub-bacia do Salto, Extrema, MG.

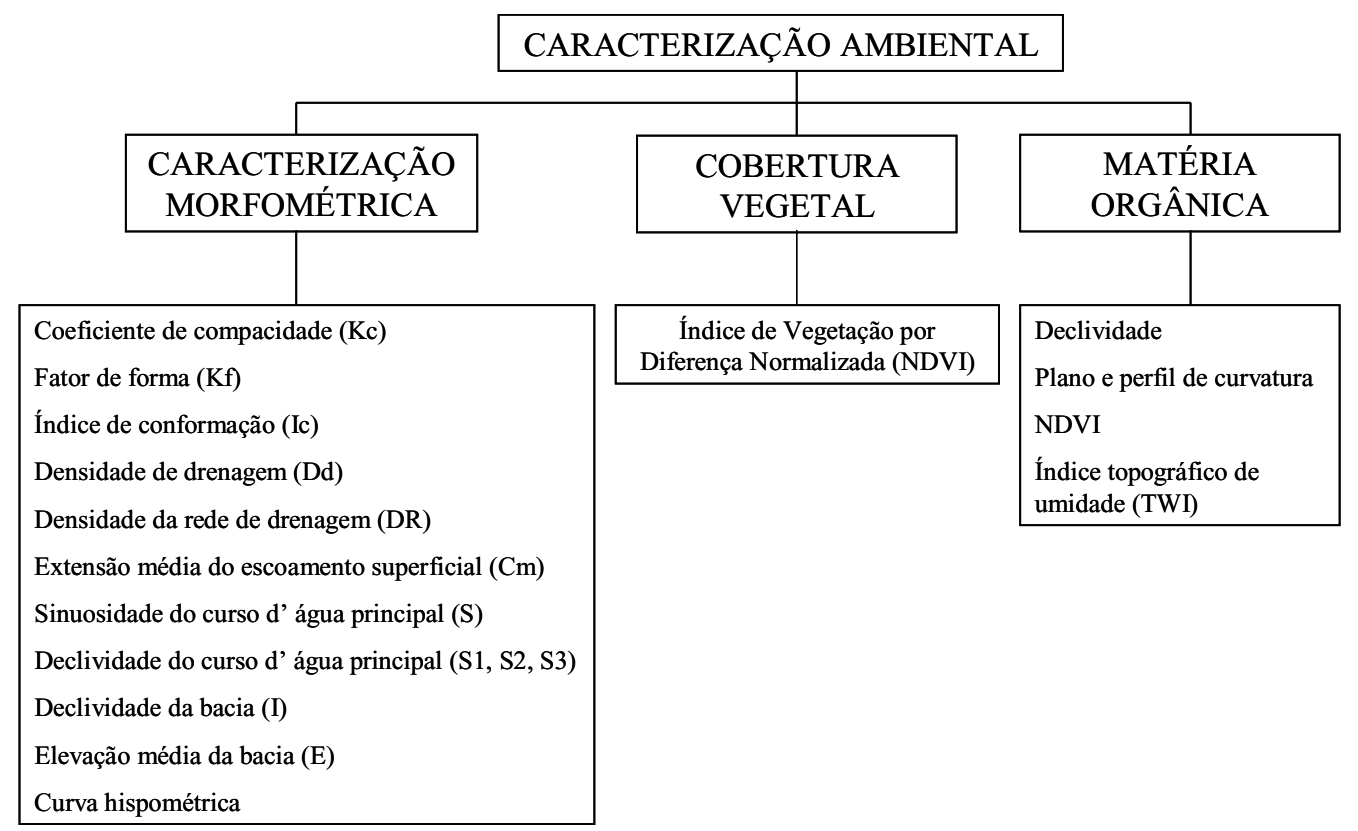

Fonte: Elaboração dos autores.

\section{Caracterização morfométrica}

A caracterização morfométrica foi realizada a partir de mapas topográficos digitalizados da Subbacia do Salto (arquivos do software AutoCAD 2004). Os coeficientes de avaliação da forma, drenagem e relevo da Sub-bacia foram calculados segundo Tucci (1997) e Vilella e Mattos (1975) e estão descritos a seguir.

Os coeficientes utilizados para quantificar a influência da forma superficial da bacia hidrográfica no seu modo de resposta à ocorrência de uma precipitação foram: a) Coeficiente de compacidade: $\mathrm{Kc}=\mathrm{P}_{\mathrm{BH}} / \mathrm{P}_{\mathrm{C}}$, onde $\mathrm{P}_{\mathrm{BH}}$ é o perímetro da bacia e $\mathrm{P}_{\mathrm{C}}$ é o perímetro de um círculo de área igual a da bacia. Quanto mais próximo da unidade for este coeficiente, mais a bacia se assemelha a um círculo. Assim, este índice pode ser interpretado da seguinte forma: 1,00 - 1,25 - bacia com alta propensão a grandes enchentes; 1,25 -1,50-bacia com tendência mediana a grandes enchentes; maior que 1,50 - bacia não sujeita a grandes enchentes. b) Fator de forma: $\mathrm{K}_{\mathrm{f}}=\mathrm{L}_{\text {médio }} / \mathrm{L}_{\mathrm{ax}}$, onde $\mathrm{L}_{\text {médio }}$ é o comprimento médio da bacia e $\mathrm{L}_{\mathrm{ax}}$ é o seu comprimento axial, em $\mathrm{km}$. $\mathrm{O}$ fator de forma pode assumir os seguintes valores: $1,00-0,75$ - sujeito a enchentes; $0,75-0,50-$ tendência mediana a enchentes; menor que $0,50-$ não sujeito a enchentes. c) Índice de conformação: $\mathrm{Ic}=\mathrm{A}_{\mathrm{BH}} / \mathrm{L}_{\mathrm{ax}}^{2}$, onde $\mathrm{L}_{\text {ax }}^{2}$ é o comprimento de um quadrado de lado igual ao comprimento axial da bacia e $\mathrm{A}_{\mathrm{BH}}$ é a área da bacia. Neste coeficiente, quanto mais próximo de 1(um) maior a propensão à enchentes, pois a forma da bacia fica cada vez mais próxima à um quadrado.

Para a análise da rede de drenagem, inicialmente o sistema foi classificado segundo metodologia de Strahler (1957), seguido das seguintes determinações: a) Densidade de drenagem: Dd (km $\left.\mathrm{km}^{-2}\right)=\sum \mathrm{L} / \mathrm{A}_{\mathrm{BH}}$, onde L é o comprimento total dos canais. b) Densidade da rede de drenagem: $\mathrm{DR}\left(\right.$ canais $\left.\mathrm{km}^{-2}\right)=\mathrm{N} / \mathrm{A}_{\mathrm{BH}}$, onde $\mathrm{N}$ é o número total de cursos d'água. c) Extensão média do escoamento superficial: $\mathrm{Cm}(\mathrm{km})=1 /(4 * \mathrm{Dd}) . \mathrm{d})$ Sinuosidade do curso d'água principal: $\mathrm{S}=\mathrm{L} / \mathrm{Lt}$, onde L é o comprimento do seu canal principal e Lt é o comprimento do seu talvegue, medido em linha reta. e) A declividade do curso d'água principal (S) foi determinada por 3 métodos: 
Declividade baseada nos extremos: S1 $(\%)=$ (h1*100) / L, onde h1 é a diferença entre cotas da nascente e o da seção de controle (ponto onde se encontra todo o escoamento superficial gerado no interior da bacia hidrográfica);

Declividade ponderada: S2 $(\%)=(\mathrm{h} 2 / \mathrm{L}) * 100$, onde h2 é a altura de um triângulo de área igual à área sob o perfil do curso d'água principal;

Declividade equivalente constante: S3 $(\%)=$ $\left[\sum \mathrm{Li} / \sum(\mathrm{Li} / \sqrt{\mathrm{Di}})\right]^{2 *} 100$, onde Li é o comprimento do respectivo trecho e Di é a declividade do respectivo trecho.

$\mathrm{Na}$ caracterização do relevo da bacia foram avaliados: a) Declividade da bacia: I $(\%)=(\mathrm{D} /$ $\left.\mathrm{A}_{\mathrm{BH}}\right) * \sum \mathrm{CNi}^{*} 100$, onde I é a declividade média da bacia (\%), D é a equidistância entre as curvas de nível (m), ¿CNi é o comprimento total das curvas de nível (m) e $A_{\mathrm{BH}}$ é área da bacia $\left(\mathrm{m}^{2}\right)$. b) Elevação média da bacia hidrográfica: $E(m)=\sum\left(\mathrm{e}_{\mathrm{i}}^{*} \mathrm{a}_{\mathrm{i}}\right){ }^{*} \mathrm{~A}_{\mathrm{BH}}$, onde, E é a elevação média da bacia (m), e é a elevação média entre duas curvas de nível consecutivas (m), e $\mathrm{a}_{\mathrm{i}}$ é a área entre as curvas de nível $\left(\mathrm{km}^{2}\right)$. c) Curva hipsométrica: obtida quando se acumula as áreas que estão acima ou abaixo de determinada altitude, apresenta a variação da elevação das áreas da bacia hidrográfica.

Índice de vegetação por diferença normalizada (NDVI)

Para análise da vegetação através do Índice de Vegetação por Diferença Normalizada (NDVI), utilizou-se a imagem do sensor TM do satélite Landsat5 do dia 03 de setembro de 2008 adquirida junto ao Instituto de Pesquisas Espaciais - INPE (INPE, 2009), onde foi composta a imagem na faixa do visível (R: banda 3, G: banda 2, B: banda 1), e foi processado o NDVI com as bandas 3 (reflectância no vermelho) e 4 (reflectância no infra-vermelho próximo) (ASRAR et al., 1984). Este índice detém a habilidade de minimizar efeitos topográficos ao produzir uma escala linear de medida, a qual varia de -1 (ausência de vegetação) a +1 (alta densidade de cobertura vegetal). As informações de NDVI foram processadas no software RSI-ENVI 4.5. As informações de rede de drenagem e declividade foram cruzadas com estes dados de NDVI no software ArcGis 9.3 com a finalidade de caracterizar as áreas mais degradadas.

Distribuição espacial dos teores de matéria orgânica do solo (MOS)

A matéria orgânica do solo (MOS) foi amostrada em 15 pontos distribuídos, aleatoriamente, em toda a Sub-bacia do Salto, sendo as coletas realizadas na camada de 0 a $20 \mathrm{~cm}$ do solo (Figura 1). A análise do teor de MOS foi realizada no Laboratório de Fertilidade do Solo na Universidade Federal de Lavras (UFLA).

A distribuição espacial dos teores estimados de matéria orgânica (MOS) foi obtida selecionando a melhor combinação dos atributos ambientais que podem ser usados para predizer o teor de MOS em toda a sub-bacia. Os atributos avaliados foram: declividade, plano e perfil de curvatura do terreno (pedoformas), NDVI e índice topográfico de umidade (TWI). A declividade é definida como sendo um plano tangente a superfície expresso como a mudança de elevação sobre certa distância. O plano e o perfil de curvatura representam as formas do relevo, sendo o primeiro referente à forma da vertente analisada em perfil, podendo ser convexa, côncava ou retilínea e o segundo à forma da vertente em plano, podendo ser convergente, divergente e planar (SIRTOLI et al., 2008).

O TWI é definido como uma função logarítmica da declividade e da área de contribuição, sendo obtido conforme a equação (BEVEN; KIRKBY, 1979):

$$
\mathrm{TWI}=\ln (\mathrm{A} / \tan \beta)
$$

onde: A é a área de contribuição; $\beta$ é a declividade.

Os atributos TWI, declividade, plano e perfil de curvatura do terreno foram gerados no software SAGA 2.0.6 (SAGA, 2010), a partir do modelo 
de elevação digital (MED), com resolução de 15 m. A influência do tamanho do pixel tem um peso significativo nas análises derivadas do MED e a escolha da resolução proporcional à escala dos dados primários deve passar por certas ponderações, dentre elas a escala original das curvas de nível e as características do relevo mapeado. Como a distância horizontal mínima encontrada entre as curvas é da ordem de $20 \mathrm{~m}$, a resolução espacial de $15 \mathrm{~m}$ mostrou-se adequada para o detalhamento do relevo apresentado na base original, considerando que resoluções menores tenderiam a gerar informações errôneas (inexistentes), enquanto resoluções maiores não detalhariam o relevo de forma satisfatória. Além disso, em áreas de topografia complexa com declives acentuados como observado na Sub-bacia dos Saltos, uma resolução grosseira $(>20 \mathrm{~m})$ pode resultar em grande incerteza, sendo necessária uma melhor resolução. O método de interpolação do MED foi baseado no modelo ANUDEM desenvolvido por Hutchinson (1989), o qual possui uma versão no software ArcGIS 9.3 executada pela ferramenta TopoToRaster (ESRI, 2009).

As combinações dos atributos foram avaliadas segundo o modelo de regressão linear múltipla relacionando os atributos da paisagem com o teor de MOS:

$$
\mathrm{Y}_{\mathrm{i}}=\beta_{0}+\beta_{1} \mathrm{X}_{\mathrm{i} 1}+\beta_{2} \mathrm{X}_{\mathrm{i} 2}+\ldots+\beta_{\mathrm{p}-1} \mathrm{X}_{\mathrm{i}, \mathrm{p}-1}+\varepsilon_{\mathrm{i}}
$$

onde: $\beta_{0}, \beta_{1}, \ldots, \beta_{\mathrm{p}-1}$, são os parâmetros; $\mathrm{X}_{\mathrm{i} 1}, \ldots, \mathrm{X}_{\mathrm{i}, \mathrm{p}-1}$ são os atributos da paisagem; $\varepsilon_{i}$ é o erro aleatório.

Foi feito o teste F de Snedecor $(\alpha=0,10)$ e todas as combinações significativas foram utilizadas para predizer o teor de MOS em toda a Sub-bacia através da ferramenta Raster Calculator do software ArcGIS 9.3 (ESRI, 2009). A utilização desta ferramenta possibilitou executar o modelo de regressão utilizando cada variável distribuída espacialmente em formato raster.

Após obter os mapas da MOS, procedeu-se a análise do viés da predição através do erro médio (EM), o qual tende a zero para métodos sem viés e da sensibilidade do modelo baseada na raiz quadrada do erro médio quadrático (RMSE), que fornece a precisão da predição sendo melhor quanto menor o seu valor (ODEH; MCBRATNEY; CHITTLEBOROUGH, 1994). A escolha da melhor combinação na predição da MOS foi realizada com base no menor valor de EM e RMSE.

$$
E M=\frac{\sum_{i=1}^{n}(z *-z)}{n} \quad R M S E=\sqrt{\frac{\sum_{i=1}^{n}(z *-z)^{2}}{n}}
$$

onde: $\mathrm{z}^{*}$ é o valor estimado da MOS pela regressão, z é o valor da MOS obtido no campo e n é o número de amostras.

Os teores de MOS foram classificados em muito baixo $\left(<0,7 \mathrm{dag}_{\mathrm{kg}}^{-1}\right)$, baixo $\left(0,71-2,0 \mathrm{dag} \mathrm{kg}^{-1}\right)$, médio $\left(2,01-4,0\right.$ dag $\left.\mathrm{kg}^{-1}\right)$, bom $(4,01-7,0$ dag $\left.\mathrm{kg}^{-1}\right)$ e muito bom $\left(>7,0 \mathrm{dag} \mathrm{kg}^{-1}\right)$ segundo Ribeiro, Guimarães e Alvarez (1999).

\section{Resultados e Discussão}

\section{Caracterização morfométrica}

Como características morfométricas básicas, mediu-se para a Sub-bacia do Salto uma área de $15,1 \mathrm{~km}^{2}$, perímetro de $18,2 \mathrm{~km}$, comprimento axial de $5,57 \mathrm{~km}$, largura média de $2,6 \mathrm{~km}$ e comprimento do talvegue de 4,2 $\mathrm{km}$.

A forma da bacia influencia no escoamento superficial durante uma determinada chuva. O coeficiente de compacidade $(\mathrm{Kc})$ foi de 1,31, indicando que a Sub-bacia, em condições normais de precipitação, possui tendência mediana a grandes enchentes. Bacias hidrográficas cujas formas se aproximam de um círculo tendem a proporcionar a conversão do escoamento superficial para um trecho pequeno do rio principal, produzindo cheias de volume superior quando comparadas a uma bacia de forma alongada.

Concordando com estes resultados, o fator de forma $\left(\mathrm{K}_{\mathrm{f}}\right)$ igual a 0,47 e o índice de conformação (Ic) de 0,48 indicaram que esta bacia não está sujeita a enchentes, pois sua forma não se assemelha a 
um quadrado. Este formato favorece o fluxo dos canais de menor para o de maior ordem hierárquica, tendendo a atingir a simultaneidade e ocasionando enchentes (RESENDE et al., 2007). Uma bacia de forma alongada produz cheias com volume inferior em razão do fluxo distribuído de maneira mais heterogênea ao longo de todo canal principal, favorecendo um escoamento mais demorado e reduzindo a probabilidade de cheias rápidas. Vários trabalhos inferiram que a forma mais alongada de uma bacia favorecia um alto nível de escoamento e baixa propensão à ocorrência de cheias, como Lopes et al. (2007) que relataram um Ic de 0,58 para a Bacia do Córrego Jataí-GO.

Quanto à rede de drenagem, a Sub-bacia foi classificada como de $4^{\mathrm{a}}$ ordem (STRAHLER, 1957), com 56 cursos d'água, apresentando um padrão subdendrítico. Adensidade da rede de drenagem(DR) foi de 3,70 canais $\mathrm{km}^{-2}$. Estes parâmetros retratam a grande disponibilidade de cabeceiras de canais ou nascentes os quais demarcam o escoamento subsuperficial, predominante nas encostas, dos canais de escoamento superficial (BOGAART; TROCH, 2006). Como zonas de convergência dos fluxos superficial e subterrâneo, as cabeceiras de cursos d'água proporcionam uma interação sinergética favorável ao processo de incisão sobre a vertente que denota um elevado risco de erosão nestas áreas, onde um manejo conservacionista do solo deve ser priorizado.

A densidade de drenagem reflete a propriedade de transmissibilidade do terreno e, consequentemente, a sua suscetibilidade à erosão. A densidade de drenagem (Dd) foi de $2,29 \mathrm{~km} \mathrm{~km}^{-2}$, sendo considerada bem drenada pois, segundo Collares (2000), valores de Dd variando de 3 a 4 km km² são, em geral, observados em sub-bacias de grande porte $\left(>40 \mathrm{~km}^{2}\right)$. Valores baixos de densidade de drenagem estão geralmente associados a regiões de rochas permeáveis e de regime pluviométrico caracterizado por chuvas de baixa intensidade ou pouca concentração da precipitação. A elevada Dd da sub-bacia indicou que a área é pouco permeável, também relatado nos estudos de Nascimento e Garcia (2005). É importante ressaltar a importância do monitoramento deste fator considerando que a utilização dos recursos hídricos decorrentes da urbanização e agricultura pode alterar a Dd vindo a influenciar na disponibilidade de água (COLLARES, 2000). O comprimento médio (Cm) do caminho percorrido pelas águas pluviais antes de se estabilizarem ao longo de um canal guarda uma estreita relação com a Dd, sendo de 109 km.

A sinuosidade dos canais é influenciada, entre outros, pela carga de sedimentos e pela declividade dos canais (TEIXEIRA et al., 2003). A sinuosidade do curso d'água principal (S) é de 1,22 e enquadra o canal como pouco tortuoso, com declividade média do curso d'água principal de 3,23\% ( $\mathrm{S} 1=5,84 \%$; $\mathrm{S} 2=2,24 \%$; $\mathrm{S} 3=1,61 \%)$. Com um índice $\mathrm{S}$ de 2,12, Lana, Alves e Castro (2001) indicaram um padrão sinuoso para os canais da bacia do Rio Tanque.

O perfil do curso d'água principal possui variação de $260 \mathrm{~m}$ da nascente até a seção de controle. Nos primeiros $1.000 \mathrm{~m}$ do curso d'água ocorre a maior declividade (cerca de $60 \%$ da diferença total de altitude, ou $160 \mathrm{~m}$ aproximadamente), indicando que a cabeceira da Sub-bacia está propícia a maiores perdas de solo. A declividade acentuada favorece os processos erosivos do solo, pois tem uma relação importante com os parâmetros hidrológicos de infiltração da água, umidade do solo, regulação do tempo do escoamento superficial e a concentração da água das chuvas no canal principal. Em declives acentuados, a menor infiltração de água favorece o aumento da velocidade do escoamento superficial e, por consequência, o poder de transporte de sedimentos e matéria orgânica. A segunda parte do curso, caracterizada por ser mais suave, pode ser uma área de deposição de sedimentos.

De acordo com a curva hispométrica, a Subbacia do Salto apresentou diferença de nível total de $540 \mathrm{~m}$, com altitude média de $1.148 \mathrm{~m}$, onde as variações desta indicam relevo mais movimentado, entre 100 a $200 \mathrm{~m}$ de altitude relativa das elevações, 
segundo classificação de Santos et al. (2005). Com comprimento total das curvas de nível de $168,8 \mathrm{~km}$ e equidistância de curvas de $20 \mathrm{~m}$, a declividade média da Sub-bacia foi de 22,3\%, caracterizando um relevo forte ondulado. Conforme Calderano Filho et al. (2003), entre 20 e $45 \%$ a superfície é fortemente inclinada e o escoamento superficial é muito rápido para a maioria dos solos, favorecendo um maior arraste de materiais na paisagem. Quanto maior a declividade, portanto, maiores devem ser os cuidados com as práticas de conservação de solo e água na Sub-bacia.

Índice de vegetação por diferença normalizada (NDVI)

O principal mecanismo de proteção da superfície do solo é a cobertura vegetal. Os locais de vegetação densa possuem reduzida erosão hídrica, pois o solo protegido do impacto da chuva aumenta a infiltração de água e diminui a concentração e o escoamento de água sobre a superfície, e também mantém a matéria orgânica, que proporciona maior agregação do solo. A composição das bandas 321 em RGB (Figura 1) auxilia na compreensão do uso e cobertura do solo, sendo possível visualizar a escassa cobertura vegetal, com ampla ocupação de pastagens (caracterizado pela tonalidade bege esverdeada na imagem), conforme observações de campo. Ao analisar a intensidade das atividades fotossintéticas pelo NDVI verificou-se igualmente que a vegetação com maior quantidade de biomassa, identificada pela coloração azul (valores mais elevados), são menos freqüentes comparadas às áreas ocupadas por cobertura vegetal de média a baixa densidade (cor cian a amarela) (Figura 3).

Os menores valores de NDVI (áreas vermelhas do mapa) caracterizam regiões de solo exposto e, portanto, mais propensas à erosão hídrica. Estas áreas, apesar de relativamente pequenas, farão com que o valor do NDVI mediano da área seja reduzido ou aumentado (Figura 3) conforme o manejo for conduzido nas atividades agropecuárias aí implantadas. Victoria, Oliveira e Grego (2009) relataram que em áreas de pastagens a variação do NDVI não é tão intensa ao longo do ano, podendo ser usado como um bom indicativo das condições de conservação do solo. Deste modo, a utilização do índice neste tipo de cobertura constitui uma importante ferramenta de monitoramento da qualidade das pastagens.

Figura 3. Imagem do Índice de Vegetação da Diferença Normalizada (NDVI) para o dia 03 de setembro de 2008, da Sub-bacia do Salto, Extrema, MG, gerado a partir das bandas Vermelho e Infravermelho Próximo do satélite Landsat5.

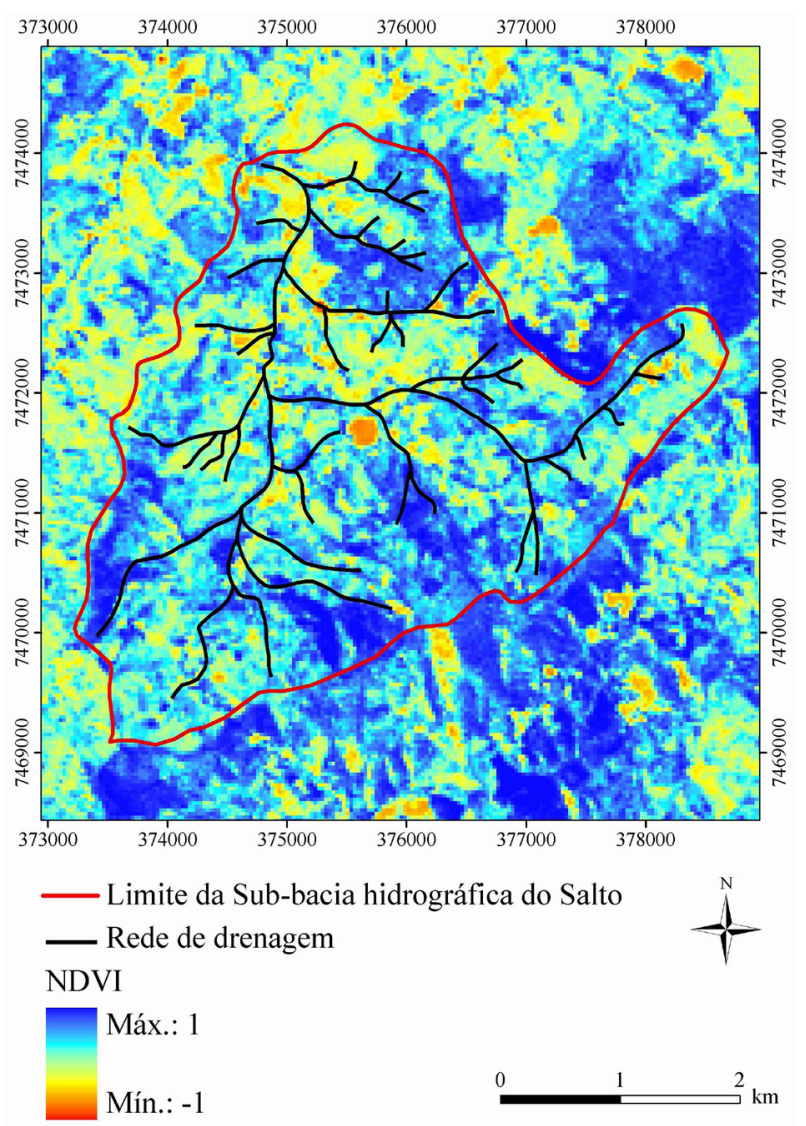

Fonte: Elaboração dos autores.

De maneira geral, as áreas mais suscetíveis à erosão em função da menor proteção do solo (menor valor de NDVI, Figura 3), situam-se ao longo da rede de drenagem principal. Um forte indício de que a região onde corre a rede de drenagem principal vem sofrendo um processo de erosão é o teor de matéria orgânica do solo (MOS), situação observada na área 
mais ao norte da Sub-bacia. Vários estudos sobre erosão, como Silva et al. (2005), têm mostrado que um dos primeiros constituintes do solo a ser levado pela erosão é a MOS, devido a sua densidade e por concentrar-se mais na superfície do solo.

Distribuição espacial dos teores de matéria orgânica do solo (MOS)

$\mathrm{Na}$ Tabela 1 encontram-se os resultados do coeficiente de determinação para as combinações dos atributos ambientais que podem ser usados para predizer o teor de MOS na Sub-bacia. Foram avaliadas 9 combinações de atributos ambientais, sendo que as combinações 3, 4, 7 e 9 foram significativas $(\alpha=0,10)$, sendo, portanto, escolhidas para predizer o teor de MOS na Subbacia. Apesar de apresentarem baixos valores de $\mathrm{R}^{2}$, a combinação entre os atributos topográficos e o teor de MOS permite o mapeamento da variável para regiões pouco amostradas e com baixo custo.
Para a Província de Heilongjiang na China, Pei et al. (2010), identificaram o TWI $\left(\mathrm{R}^{2}=0,23\right)$ como o índice com correlação mais forte entre os atributos topográficos e a MOS sendo utilizado no mapeamento da MOS para a província. Conforme se observa na Tabela 2, os valores de EM e RSEM foram menores para a combinação 4, que considera a influência da declividade, perfil de curvatura, NDVI e TWI na obtenção do teor de MOS. A declividade, atributo que também é inerente à análise do perfil de curvatura bem como do TWI, representaram, portanto, os principais atributos na predição do teor de MOS na Sub-bacia do Salto, concordando com Moore et al. (1993). Os autores verificaram que o TWI e a declividade foram os atributos do relevo que mais se correlacionaram com diferentes atributos medidos do solo. Segundo Gallant e Wilson (2000), a declividade afeta diretamente a velocidade do fluxo superficial de água e consequentemente o teor de água no solo e o potencial de erosão.

Tabela 1. Coeficientes de correlação dos atributos selecionados na predição da matéria orgânica (MOS) na Sub-bacia do Salto, Extrema, MG.

\begin{tabular}{cll}
\hline Identificação & \multicolumn{1}{c}{ Combinações de atributos $x$ MOS } & \multicolumn{1}{c}{$\mathrm{R}^{2}$} \\
\hline 1 & Declive, plano de curvatura, perfil de curvatura, NDVI, TWI & 0,56 \\
2 & Declive, plano de curvatura, perfil de curvatura, TWI & 0,45 \\
3 & Declive, plano de curvatura, perfil de curvatura, NDVI & $0,55^{*}$ \\
4 & Declive, perfil de curvatura, NDVI, TWI & $0,56^{*}$ \\
5 & Declive, plano de curvatura, NDVI, TWI & 0,29 \\
6 & Plano de curvatura, perfil de curvatura, NDVI, TWI & 0,50 \\
7 & Declive, perfil de curvatura, NDVI & $0,53^{*}$ \\
8 & Declive, plano de curvatura, NDVI & 0,28 \\
9 & Plano de curvatura, perfil de curvatura, NDVI & $0,49^{*}$ \\
\hline
\end{tabular}

${ }^{1}$ Combinação realizada para os atributos em cada um dos pontos de MOS amostrados no campo (Figura 1). *Significativo pelo teste $\mathrm{F}$ de Snedecor, $\operatorname{com} \alpha=0,10$. Fonte: Elaboração dos autores.

Tabela 2. Erro médio (EM) e raiz quadrada do erro médio quadrático (RMSE) para as combinações selecionadas na predição da matéria orgânica (MOS) na Sub-bacia do Salto, Extrema, MG.

\begin{tabular}{clcc}
\hline Identificação & \multicolumn{1}{c}{ Combinações de atributos $x$ MOS $^{1}$} & EM & RSEM \\
\hline 3 & Declive, plano de curvatura, perfil de curvatura, NDVI & 0,8356 & 1,78 \\
4 & Declive, perfil de curvatura, NDVI, TWI & $-0,0913$ & 1,62 \\
7 & Declive, perfil de curvatura, NDVI & $-0,1029$ & 1,62 \\
9 & Plano de curvatura, perfil de curvatura, NDVI & 1,3202 & 1,97 \\
\hline
\end{tabular}

${ }^{1}$ Combinação realizada para os atributos em cada um dos pontos de MOS amostrados no campo (Figura 1).

Fonte: Elaboração dos autores. 
De acordo com o mapa gerado pela combinação 4 para a Sub-bacia do Salto, os teores de MOS com maior expressão geográfica na Sub-bacia (cerca de $80 \%$ ) foram classificados como "baixo" e "médio" (Figura 4), enquanto a faixa de classificação "muito bom" foi insignificante. As áreas com baixos teores de MOS estão associadas à rede de drenagem principal, que são os locais com pouca cobertura vegetal (baixo a médio NDVI), demonstrando a necessidade de implantação de práticas de conservação do solo e da água aliadas à recomposição florestal das Áreas de Preservação Permanente (APP).

Figura 4. Distribuição espacial da $\operatorname{MOS}\left(\mathrm{g} \mathrm{kg}^{-1}\right)$ estimada, segundo classificação de Ribeiro, Guimarães e Alvarez (1999), por classe de solo e para a área total da Sub-bacia do Salto, Extrema, MG.

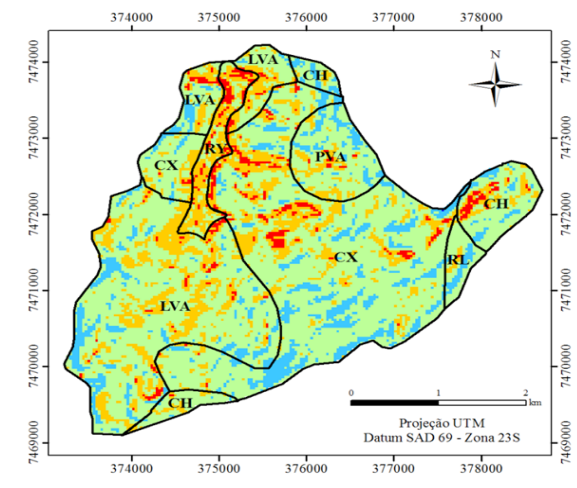

LVA: Latossolo Vermelho-Amarelo CX: Cambissolo Háplico CH: Cambissolo Húmico RY: Neossolo Flúvico RL: Neossolo Litólico PVA: Argissolo Vermelho-Amarelo

Fonte: Elaboração dos autores.

\section{Teor de matéria orgânica do solo MOS $($ dag kg-1)}

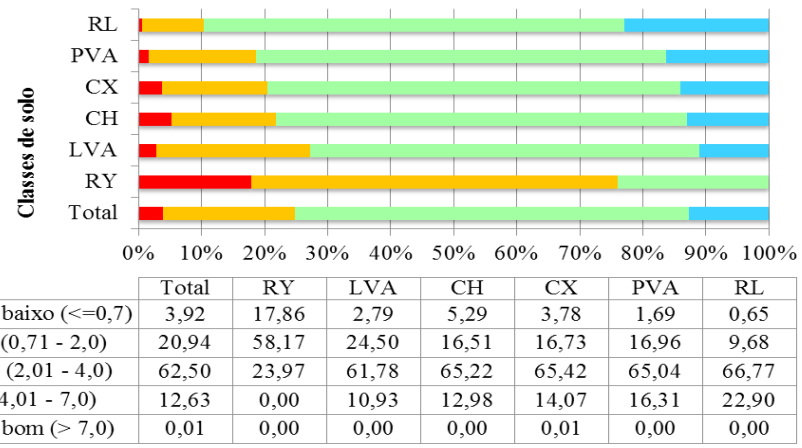

Os maiores teores de MOS (Figura 4) foram encontrados nas áreas com vegetação mais densa (Figura 3), situados principalmente nas cabeceiras da Sub-bacia. As cabeceiras e nascentes são áreas de preservação permanente, contudo, a falta de vegetação e consequente declínio da MOS acarreta maior evolução dos processos erosivos quando comparado a áreas de relevo menos movimentado, podendo causar alterações nos regimes de suprimento de água e nutrientes. Este fato pode ser observado na parte leste da Sub-bacia (Figuras 3 e 4), onde se localizam as maiores altitudes (Figura 1).

Para cada classe de solo foi avaliada a porcentagem da área ocupada por classe de MOS (Figura 4). Todas as classes de solo possuem mais de $60 \%$ da sua área com teores de MOS considerados médios com exceção do Neossolo Flúvico, o qual apresentou 58\% da sua área com baixos teores de MOS. Estes resultados corroboram observações de Resende et al. (2007) a respeito da interação solo/relevo, água e vegetação em microbacias hidrográficas. A natureza deposicional recente de sedimentos retarda a evolução do Neossolo Flúvico (RY), constituindo um ambiente mais conservador; contudo, segundo os autores, é um solo propenso ao encrostamento da superfície provocado pelo impacto direto das gotas de chuva que, dependendo da pedoforma, pode favorecer o escoamento superficial e o arraste de MOS. A MOS diminui muito a possibilidade de encrostamento, pois auxilia na agregação do solo evitando o deslocamento e rearranjo de partículas, principalmente silte e areia fina, e consequentemente, reduzindo a erosão (RESENDE, 1985). 
Para os Cambissolos Háplico (CX) e Húmico (CH) e Neossolo Litólico (RL), esta mesma facilidade de encrostamento superficial aliada à escassa cobertura vegetal, ao relevo forte ondulado da Sub-bacia e ao escoamento superficial sazonalmente muito intenso, facilitam a erosão e a remoção de MOS, aumentando a instabilidade destes solos. No caso do Latossolo VermelhoAmarelo (LVA), quanto mais movimentado o relevo, maior a ocorrência da pedoforma convexa, a qual favorece a erosão e é mais frequente em solos mais novos (RESENDE et al., 2007), a exemplo do RY, RL, CX e CH (Figura 4).

A caracterização morfométrica da Sub-bacia hidrográfica do Salto apontou uma bacia de forma intermediária, entre circular e arredondada, cuja tendência a enchentes é mediana a baixa, de drenagem eficiente com padrão subdendrítico e de quarta ordem.

A altitude média da Sub-bacia é de $1.148 \mathrm{~m}$ com uma declividade média de $22,3 \%$. O relevo forte ondulado da Sub-bacia pode favorecer o escoamento lateral de água no solo, tornando esta sub-bacia susceptível a erosão hídrica, sendo necessária a adoção de um manejo conservacionista que possibilite a retenção e o escoamento disciplinado da água.

O NDVI foi eficiente em avaliar as variações de densidade das diferentes coberturas vegetais presentes, podendo ser utilizado como ferramenta de identificação do uso e ocupação do solo. Segundo observações de campo, a região estudada apresenta grande parte de sua área ocupada por pastagens degradadas, o que compromete o acúmulo de MOS e consequentemente, a conservação do solo. A vegetação com maior quantidade de biomassa ocorre principalmente nas áreas de cabeceira, localizadas nas regiões mais altas.

$\mathrm{O}$ conjunto de atributos que melhor estimou o teor de MOS foi declividade, perfil de curvatura, NDVI e TWI. A declividade representou o principal atributo na predição do teor de MOS na Sub-bacia. O teor médio de MOS estimada na Sub-bacia foi de 2,01 a 4,00 dag $\mathrm{kg}^{-1}$, sendo os maiores teores encontrados nas áreas com vegetação mais densa, situados principalmente em áreas de maior altitude (cerca de $1.600 \mathrm{~m}$ ) nas cabeceiras da Sub-bacia.

\section{Referências}

AGÊNCIA NACIONAL DE ÁGUAS - ANA. Programa produtor de água. ANA: Brasília. Disponível em: $<$ http:// www.ana.gov.br>. Acesso em: 08 ago. 2008.

ASRAR, G.; FUCHS, M.; KANEMASU, E. T.; HATFIELD, J. L. Estimating absorbed photosynthetic radiation and leaf area index from spectral reflectance in wheat. Agronomy Journal, Madison, v. 76, n. 2, p. 300306, 1984.

BERTONI, J.; LOMBARDI NETO, F. Conservação do solo. 5. ed. São Paulo: Ícone, 2005. 355 p.

BEVEN, K. J.; KIRKBY, M. J. A physically based variable contributing areamodel of basin hydrology. Hydrology Science, Wallingford, v. 24, n. 1, p. 43-69, 1979.

BOGAART, P. W.; TROCH, P. A. Curvature distribution within hillslopes and catchments and its effect on the hydrological response. Hydrology and Earth System Sciences, Alemanha, v. 10, n. 6, p. 925-936, 2006.

BRASIL. Lei $n^{\circ} 9.433$, de 08 de janeiro de 1997. Institui a Política Nacional de Recursos Hídricos (PNRH) e cria o Sistema Nacional de Gerenciamento de Recursos Hídricos. Brasília, 1997. Disponível em: <http://www. planalto.gov.br/ccivil_03/LEIS/L9433.htm.>. Acesso em: 23 mar. 2010.

CALDERANO FILHO, B.; PALMIERI, F.; GUERRA, A. J. T.; CALDERANO, S. B.; FIDALGO, E. C. C.; PRADO, R. B.; SILVA, E. F. da; CAPECHE, C. L.; FONSECA, O. O. M. da. Levantamento de solos e avaliação da aptidão agrícola das terras da microbacia Janela das Andorinhas, no município de Nova Friburgo, RJ. Rio de Janeiro: Embrapa Solos, 2003. 52 p. (Boletim de Pesquisa e Desenvolvimento, n. 27).

COLLARES, E. G. Avaliação de alterações em redes de drenagem de microbacias como subsídio ao zoneamento geoambiental de bacias hidrográficas: aplicação na bacia do Rio Capivari. 2000. Tese (Doutorado em Geotecnia) - Escola de Engenharia. Universidade de São Paulo, São Carlos.

EMPRESA BRASILEIRA DE PESQUISA AGROPECUÁRIA - EMBRAPA. Sistema brasileiro de classificação de solos. 2. ed. Rio de Janeiro: CNPS, 2006. $306 \mathrm{p}$. 
ENVIRONMENTAL SYSTEMS RESEARCH INSTITUTE- ESRI. ArcGIS Professional GIS for the desktop, version 9.3. Redlands, 2009. 1 CD-ROM.

GALLANT, J. C.; WILSON, J. P. Primary topographic attributes. In: WILSON, J. P.; GALLANT, J. C. (Ed.). Terrain analysis: principles and applications. New York: John Wiley, 2000, p. 51-85.

HUTCHINSON, M. F. A new procedure for gridding elevation and stream line data with automatic removal of spurious pits. Journal of Hydrology, Amsterdam, v. 106, n. 3-4, p. 211-232, 1989.

INSTITUTO DE PESQUISAS ESPACIAIS - INPE. Catálogo de imagens LANDSAT. 2009. Disponível em: $<$ http://www.inpe.br>. Acesso em: 26 ago. 2009.

LAL, R. World cropland soils as a source or sink for atmospheric carbono. Advances in Agronomy, Newark, v. 71, n. 1, p. 145-191, 2001.

LANA, C. E.; AlVeS, J. M. P.; CASTRO, P. T. A. Análise morfométrica da bacia do rio do Tanque, $\mathrm{MG}-$ Brasil. Revista da Escola de Minas, Ouro Preto, v. 54, n. 2, p. 1211-1212, 2001.

LOPES, R. M.; ASSUNÇÃO, H. F.; SCOPEL, I.; CABRAL, P. J. B. Características fisiográficas e morfométricas da microbacia do Córrego Jataí no município de Jataí-GO. Geoambiente on-line, Jataí, v. 9, n. 9, p. 149-163, 2007.

MOORE, I. D.; GEISSLER, P. E.; NIELSEN, G. A.; PETERSON, G. A. Soil attribute prediction using terrain analysis. Soil Science Society of America Journal, Madison, v. 57, n. 2, p. 443-452, 1993.

MOREIRA, M. A.; SHIMABUKURO, Y. E. Cálculo do indice de vegetação a partir do sensor AVHRR In: Aplicações ambientais brasileiras dos satélites NOAA e TIROS-N. São Paulo: Oficina de Textos, 2004, cap.4, p. 79-101.

NASCIMENTO, P. S. R.; GARCIA, G. J. Compartimentação fisiográfica para análise ambiental do potencial erosivo a partir das propriedades da rede de drenagem. Engenharia Agrícola, Jaboticabal, v. 25, n. 1, p. 231-241, 2005.

ODEH, I. O. A.; MCBRATNEY, A. B.; CHITTLEBOROUGH, D. J. Spatial prediction of soil properties from landform attributes derived from a digital elevation model. Geoderma, Amsterdam, v. 63, n. 3-4, p. 197-214, 1994.

PEI, T.; QIN, C. Z.; ZHU, A. X.; YANG, L.; LUO, M.; LI, B.; ZHOU, C. Mapping soil organic matter using the topographic wetness index: a comparative study based on different flow-direction algorithms and kriging methods. Ecological Indicators, Holanda, v. 10, n. 3, p. 610-619, 2010.
RESENDE, M. Aplicação de conhecimentos pedológicos à conservação de solos. Informe Agropecuário, Belo Horizonte, v. 11, n. 1, p. 3-18, 1985.

RESENDE, M.; CURI, N.; REZENDE, S. B. de; CORRÊA, G. F. Pedologia: base para distinção de ambientes. 5. ed. rev. Lavras: UFLA, 2007. 322 p.

RIBEIRO, A. C.; GUIMARÃES, P. T. G.; ALVAREZ, V. H. Recomendações para uso de corretivos e fertilizantes em Minas Gerais - $5^{a}$ Aproximação. Viçosa: Comissão de Fertilidade do Solo do Estado de Minas Gerais, 1999. $359 \mathrm{p}$.

SAGA user group association. SAGA 2.0.6 - System for automated geoscientific analyses. Version: 2.0.6. 2010. Disponível em: < http://www.saga-gis.org $>$. Acesso em: 15 jul. 2011.

SANTOS, R. D.; LEMOS, R. C.; SANTOS, H. G.; KER, J. C.; ANJOS, L. H. C. Manual de descrição e coleta de solo no campo. 5.ed. Viçosa: Sociedade Brasileira de Ciência do Solo, 2005. 100 p.

SILVA, A. M.; SILVA, M. L. N.; CURI, N.; LIMA, J. M.; AVANZI, J. C.; FERREIRA, M. M. Perdas de solo, água, nutrientes e carbono orgânico em Cambissolo e Latossolo sob chuva natural. Pesquisa Agropecuária Brasileira, Brasília, v. 40, n. 12, p. 1223-1230, 2005.

SIRTOLI, A. E.; SILVEIRA, C. T. da; MANTOVANI, L. E.; SIRTOLI, A. R. A.; OKA-FIORI, C. Atributos do relevo derivados de modelo digital de elevação e suas relações com solos. Scientia Agraria, Curitiba, v. 9, n. 3, p. 317-329, 2008.

STRAHLER, A. N. Quantitative analysis of watershed geomorphology. Transactions of the American Geophysical Union, Washington, v. 36, n. 6, p. 913-920, 1957.

TEIXEIRA, W.; TOLEDO, M. C. M. de; FAIRCHILD, T. R.; TAIOLI, F. Decifrando a terra. 2. ed. São Paulo: Oficina de Textos, 2003. 558 p.

TUCCI, C. E. M. (Org.). Hidrologia: ciência e aplicação. 2. ed. Porto Alegre: Editora da Universidade, ABRH, 1997. (Coleção ABRH de Recursos Hídricos).

VICTORIA, D. C.; OLIVEIRA, A. F.; GREGO, C. R. Análise harmônica de séries temporais de imagens NDVI/ MODIS para discriminação de coberturas vegetais. In: SIMPÓSIO BRASILEIRO DE SENSORIAMENTO REMOTO, 14., Natal, 2009. Anais... Natal: INPE, 2009. p. 1589-1596.

VILELLA, S. M.; MATTOS, A. Hidrologia aplicada. São Paulo, McGraw-Hill, 1975. 245 p.

WILSON, J. P.; GALLANT, J. C. Digital terrain analysis. In: __ (Ed.). Terrain analysis: principles and applications. Los Angeles: University of Southern California, 2000. p. 1-27. 